\title{
Reação de Metilação da Lisina Metiltransferase e Silenciamento de Genes no Rastreio do Desenvolvimento do Câncer
}

\author{
Lysine Methyltransferase Methylation Reaction and Gene Silencing in the Screening of Cancer Development \\ Reacción de Metilación de Lisina Metiltransferasa y Silenciamiento de Genes en la Detección del Desarrollo del Cáncer
}

\begin{abstract}
RESUMO
Objetivo: Investigar os diferentes papeis da metilação da proteína lisina metiltransferase H3K9 no silenciamento de genes, associados ao rastreio do desenvolvimento do câncer. Métodos: Trata-se de uma revisão de literatura, a partir da apresentação e da síntese dos estudos selecionados acerca do papel da metilação da proteína lisina metiltransferase H3K9 e silenciamento de genes. As bases de dados utilizadas na triagem de material, foram as plataformas de busca: Nature, Medical Literature Analysis and Retrieval System Online (Medline), Scientific Electronic Library Online (SciELO) e Science Direct. Resultados: Foram identificados 32 estudos relacionados ao tema proposto. Após triagem dos registros obtidos pela busca nos bancos de dados, obteve-se como produto final dos artigos incluídos na revisão, 6 trabalhos que retratavam a proposta do estudo. Conclusão: Apresentou-se uma visão geral atualizada e específica dos efeitos celulares e moleculares subjacentes à atividade de H3K9 no desenvolvimento e progressão do câncer.
\end{abstract}

DESCRITORES: Câncer; Metilação; Lisina; Metiltransferase.

\section{ABSTRACT}

OObjective: To investigate the different roles of lysine methyltransferase H3K9 methylation in gene silencing associated with screening for cancer development. Methods: This is a literature review, based on the presentation and synthesis of selected studies on the role of lysine methyltransferase H3K9 protein methylation and gene silencing. The databases used in the material screening were the search platforms: Nature, Medical Literature Analysis and Retrieval System Online (Medline), Scientific Electronic Library Online (SciELO) and Science Direct. Results: 32 studies related to the proposed theme were identified. After screening the records obtained by searching the databases, 6 works that portrayed the study proposal were obtained as the final product of the articles included in the review. Conclusion: An updated and specific overview of the cellular and molecular effects underlying the activity of H3K9 on cancer development and progression is presented.

DESCRIPTORS: Cancer; Methylation; Lysine; Methyltransferase

\section{RESUMEN}

Objetivo: Investigar los diferentes roles de la metilación de la lisina metiltransferasa H3K9 en el silenciamiento génico asociado con el cribado del desarrollo del cáncer. Métodos: Se trata de una revisión de la literatura, basada en la presentación y síntesis de estudios seleccionados sobre el papel de la metilación de la proteína lisina metiltransferasa H3K9 y el silenciamiento génico. Las bases de datos utilizadas en la selección del material fueron las plataformas de búsqueda: Nature, Medical Literature Analysis and Retrieval System Online (Medline), Scientific Electronic Library Online (SciELO) y Science Direct. Resultados: se identificaron 32 estudios relacionados con el tema propuesto. Tras el cribado de los registros obtenidos mediante la búsqueda en las bases de datos, se obtuvieron 6 trabajos que retrataban la propuesta de estudio como producto final de los artículos incluidos en la revisión. Conclusión: Se presenta una descripción general actualizada y específica de los efectos celulares y moleculares que subyacen a la actividad de HЗK9 en el desarrollo y la progresión del cáncer.

DESCRIPTORES: Cáncer; Methylation; Lisina; Metiltransferasa

RECEBIDO EM: 31/08/2021 APPROVADO EM: 12/11/2021

\section{Murilo Tavares Amorim}

Biomédico, Mestrando em Biologia de Agentes Infecciosos e Parasitários pela Universidade Federal do Pará (UFPA), Belém PA

ORCID: 0000-0002-9769-2183 


\section{artigo}

Amorim, M. T., Cruz, A. C. R., Ferreira, J. F. L., Oliveira, D. J. S., Melo, C. A., Pinto, C. C., Neto, W. F. F., Holanda, G. M.

Reação de Metilação da Lisina Metiltransferase e Silenciamento de Genes no Rastreio do Desenvolvimento do Câncer

\section{Ana Cecília Ribeiro Cruz}

Biomédica, Doutora em Biologia Parasitária pela Fundação Oswaldo Cruz e Orientadora do Programa de Pós Graduação em Biologia de Agentes Infecciosos e Parasitário - UFPA, Belém - PA.

ORCID: 0000-0002-4607-9346

\section{Jardel Fábio Lopes Ferreira}

Biomédico, Doutorando em Biologia de Agentes Infecciosos e Parasitários pela Universidade Federal do Pará (UFPA) Belém PA

ORCID: 0000-0001-6839-8156

Deborah de Jesus Sizo Oliveira

Biomédica pelo Centro Universitário Fibra, Belém-PA

ORCID: 0000-0001-6678-1258

\section{Célio Amoêdo de Melo}

Biomédico, Especialista em Citologia Clínica pelo Centro de Ensino Superior do Pará, Belém-PA

ORCID: 0000-0001-8618-7803

\section{Caroline Carvalho Pinto}

Biomédica, Mestranda em Virologia pelo Instituto Evandro Chagas, Ananindeua - PA

ORCID: 0000-0003-4885-4823

\section{Walter Félix Franco Neto}

Biomédico, Mestre em Virologia pelo Instituto Evandro Chagas.

ORCID: 0000-0003-2317-4735

\section{Gustavo Moraes Holanda}

Biomédico, Mestre em Virologia pelo Instituto Evandro Chagas, ORCID: https://orcid.org/0000-0003-2317-4735, Biólogo, Doutor em Virologia pelo Instituto Evandro Chagas, Docente dos cursos de Biomedicina, Enfermagem e Nutrição da Universidade da Amazônia (UNAMA), Belém - PA

ORCID: 0000-0001-6730-9254

\section{INTRODUÇÃO}

Câncer destaca-se por ser um dos principais objetos de estudo na atualidade, devido a sua relevância epidemiológica, ocasionada principalmente, mediante os impactos globais sociais e econômicos decorrentes do aumento de sua incidência, uma vez que este, se estabelece como sendo o segundo maior causador de mortes no mundo, segundo dados apresentados pela Organização Mundial da Saúde ${ }^{1}$.

Nessa perspectiva, têm sido realizados diversos estudos com ênfase na compreensão do surgimento dessa doença, objetivando rastrear diversas vias de sinalização que podem desencadear o surgimento do câncer. Com base nas que se encontram sob constante evolução acerca da concepção desses fatores, destaca-se a metilação do
A transferência

da informação

genética tem sido

tradicionalmente

descrita como

um fluxo direto

e de prevalência

contínua, do DNA

para o RNA e para

as proteínas.
DNA e alteração das histonas, responsáveis por apresentar um papel na expressão de genes, com modificaçóes relatadas em diversos tipos de câncer ${ }^{2,3}$.

A transferência da informação genética tem sido tradicionalmente descrita como um fluxo direto e de prevalência contínua, do DNA para o RNA e para as proteínas. Apesar disso, essa definição clássica, sob a qual se estabelece a premissa do dogma central da biologia molecular, não é capaz de englobar a complexidade biológica de como diversas proteínas e metabólitos agem, influenciando esses produtos moleculares, em caráter hereditário ${ }^{4}$.

Quanto em relação às funções biológicas, a metilação da proteína, em termos gerais, busca interferir no destino celular das proteínas, modulando a sua estabilidade funcional, sua localização e subsequente interação com seus ligantes associados. 
Portanto, são previstas marcas de metilação de histonas, caracterizadas principalmente devido a sua forte associação com a modulação epigenética da transcrição $0^{5,6}$.

Partindo-se de uma primeira análise, verifica-se que as histonas - tipo específico de proteínas presentes nos lisossomos - estão susceptíveis a variados tipos de modificações covalentes, sendo estas; a metilação; e acetilação; a ubiquitilação; a sumoilação e a fosforilação. A metilação do DNA é a modificação epigenética mais bem caracterizada na literatura e reconhecida como sendo um mecanismo de silenciamento de genes ${ }^{7}$.

Esse processo consiste basicamente na adição de um radical metil ( $\mathrm{CH} 3)$ no carbono 5 de Citosina, geralmente seguida por Guanina (dinucleotídeo CpG), catalisada por enzimas DNA metiltransferases (DNMTs). Dentre as diversas famílias de proteínas expressas, tem-se a Lisina Metiltransferase (PKMT), que atua principalmente na metilação de resíduos de lisinas nas histonas, podendo catalisar a transferência de até três grupos metilas para resíduos de lisina ${ }^{7.8}$. Assim, em PKMT, tem-se a Histona-lisina $\mathrm{N}$-metiltransferase ${ }^{2}$ (G9a), responsável pela metilação da Lisina 9 na histona $\mathrm{H} 3$, associadas à metiltransferase $\mathrm{H} 3 \mathrm{~K} 9$, indicando acetilação do 9 resíduo de lisina da histona ${ }^{3}$, sendo os genes, ativados se tal marca for acetilada e silenciados se houver sua metilação . Esta proteína é diretamente responsável pelo silenciamento de genes envolvidos na fase embrionária sendo relatado em diversos tipos de câncer, através da manutenção da via de biossíntese da serina-glicina ${ }^{2,9}$.

Sobre a ligação entre a metilação do H3K9 e do DNA, em Neurospora, DNA metiltransferase (DIM-2) forma um complexo com a Proteína de Heterocromatina 1 (HP1) e em seguida, o DIM-5 Histona Lisina Metiltransferase (HKMT) metila H3K9 de modo a formar H3K9me310,11. Após esse evento, o complexo DIM-2-HP1 é recrutado para um lócus de nucleossomos positivos para $\mathrm{H} 3 \mathrm{~K} 9 \mathrm{me} 3$, por meio da ligação de HP1 a H3K9me3, induzindo a metilação de DNA. Já em Arabidopsis, a metilação do DNA e do H3K9 independem quanto à função e relação entre si. Dessa forma, é possível verificar que o domínio Set ou Ring do HKMT KRYPTONITE (KYP) se liga ao DNA metilado e como consequência o KYP busca os nucleossomos, com a finalidade de metilar $\mathrm{H} 3 \mathrm{~K} 9$, de modo a formar $\mathrm{H} 3 \mathrm{~K} 9 \mathrm{me}$ 2. Assim, H3K9me2 recupera a DNA metiltransferase Cromometilase 3, com a finalidade de induzir a metilação do $\mathrm{DNA}^{12,13}$.

Em células de mamíferos, a metilação do DNA em repetições satélites grandes, é reduzida em histonas lisinas metiltransferases - SUV39h1 e SUV39h2 - com duplo knockout em células estaminais embrionárias (ES)14,15. Assim, a metilação de H3K9 mediada por SUV39h1 e recrutamento de HP1 assume um papel de fundamental importância no recrutamento de heterocromatina pericentromérica de HP1 $\alpha$ e HP1 $\beta$, interagindo com a DNA metiltransferase $3 \mathrm{~b}^{14,15}$.

No entanto, sob outra perspectiva, também são descritas outras alterações pontuais em células de mamíferos. Em ES, foi descrita metilação de DNA dependente de G9a - GLP e independente da atividade da histona metiltransferase in vivo, ou seja, o G9a cataliticamente inativo, restaura parcialmente o padrão de metilação aberrante de DNA em células G9a. Já em HeLa, DNMT1 interage com G9a, regulando o carregamento da cromatina de G9a, e o knockdown de DNMT1, induzindo redução dos níveis de $\mathrm{H} 3 \mathrm{~K} 9 \mathrm{me} 2^{16,17}$.

Nessa perspectiva, apesar das propriedades químicas da metilação da proteína PKMT tornarem desafiador do ponto de vista técnico, obter o rastreio dos mecanismos biológicos associados a influência no desenvolvimento do câncer, permite sugerir que a metilação pode não ser ocasionalmente susceptível em outros tipos de modificações pós-tradução. Ainda, é comumente aceitável que uma proteína não existe em uma conformação rígida, permanente e estável, mas em um conjunto inespecífico de diversos parâmetros conformacionais presentes em um equilíbrio variável e inconstante ${ }^{17,18}$. Dessa forma, o presente estudo visa realizar uma revisão que aborde os diferentes papeis da metilação da proteína lisina metiltransferase $\mathrm{H} 3 \mathrm{~K} 9$ e silenciamento 


\section{artigo}

Amorim, M. T., Cruz, A. C. R., Ferreira, J. F. L., Oliveira, D. J. S., Melo, C. A., Pinto, C. C., Neto, W. F. F., Holanda, G. M.

Reação de Metilação da Lisina Metiltransferase e Silenciamento de Genes no Rastreio do Desenvolvimento do Câncer

de genes, de modo a sugerir e relacionar parâmetros confluentes entre si, associados ao rastreio do desenvolvimento de diversos tipos de câncer.

\section{MÉTODOS}

O presente estudo, possui abordagem observacional, transversal e base qualitativa. Trata-se de uma revisão do tipo integrativa, fundamentada a partir da apresentação e da síntese dos estudos selecionados acerca do papel da metilação da proteína lisina metiltransferase $\mathrm{H} 3 \mathrm{~K} 9$ e silenciamento de genes, de modo a relacionar ao rastreio do desenvolvimento e do prognóstico de diversos tipos de câncer descritos. Para obtenção, registro e análise dos produtos obtidos na pesquisa, foram percorridas as seguintes etapas: (1) Identificação do tema e formulação da questão de pesquisa; (2) Elaboração dos critérios de inclusão e exclusão de artigos; (3) Construção de instrumentos para coleta de dados relevantes dos artigos encontrados; (4) Avaliação e análise dos artigos selecionados na pesquisa; 5) interpretação e discussão dos resultados obtidos; (6) Apresentação da revisão juntamente com referencial teórico acerca do tema.

O levantamento dos estudos obtidos na literatura, de modo a realizar o registro dos resultados, foi realizado no período de janeiro a abril de 2021. As bases de dados utilizadas na triagem de material, foram as plataformas de busca: Nature, Medical Literature Analysis and Retrieval System
Online (Medline), Scientific Electronic Library Online (SciELO) e Science Direct. $\mathrm{O}$ estudo conferiu prioridade a trabalhos publicados na língua inglesa e portuguesa. As palavras-chave pesquisadas foram: Câncer, H3K9, Lisina e Metiltransferase. Para realizar o apuramento dos artigos, determinou-se como critérios de inclusão: artigos publicados entre 2011-2020, privilegiando estudos recentes acerca da temática; textos disponibilizados na íntegra; pesquisas científicas classificadas como originais e indexadas nas bases de dados e artigos disponíveis nos idiomas português e inglês. Ainda, foram excluídos: artigos publicados anteriormente ao ano de 2011; publicações repetidas em duas ou mais bases de dados; publicações disponíveis somente em forma de resumo; estudos em formato de carta; trabalhos que não tiveram como sujeitos de estudo a abordagem do tema proposto.

Ao final, foram extraídos os dados de utilidade nos artigos com base em informações estabelecidas de acordo com as seguintes variáveis: (i) o autor, e ano de publicação do artigo; (ii) estudos moleculares, relatos de caso e epidemiologia; (iii) mecanismos de interação e análise de expressão de proteínas; (iv) relevância, originalidade e impacto do estudo na saúde pública; (v) objetivo, contribuição e conclusão do estudo. Dessa forma, sob análise qualitativa, os estudos foram selecionados a partir da análise dos títulos. Foram designados os artigos para avaliação independente dos resumos. Os resumos dos artigos selecionados foram lidos na íntegra e forneceram resultados significativos, demonstrados em quadros, posteriormente.

\section{RESULTADOS}

Foram identificados após busca sistematizada, o total de 32 estudos relacionados ao papel da metilação da proteína lisina metiltransferase $\mathrm{H} 3 \mathrm{~K} 9$ e silenciamento de genes, associados ao rastreio do desenvolvimento de diversos tipos de câncer, sendo estes registrados em correspondência quantitativa após delimitação dos critérios de exclusão, configuradas segundo as variáveis estabelecidas, com SciELO ( $\mathrm{n}=13$ ) ScienceDirect $(\mathrm{n}=7)$, Medline $(\mathrm{n}=9)$ e Nature $(\mathrm{n}=3)$, a partir da busca fundamentada na restrição dos filtros estabelecidos pelas plataformas de acesso, intercalação cruzada dos descritores e adição dos operadores, obedecendo os critérios de inclusão e exclusão, de modo a restringir os parâmetros de busca e tornar susceptível o processo de seleção dos estudos encontrados. Após triagem dos registros obtidos pela busca nos bancos de dados, obteve-se como produto final dos artigos incluídos na revisão, 6 trabalhos que retratavam a proposta do tema, sendo o restante descartado a partir dos seguintes critérios; Inadequação do período de busca $(n=6)$; Divergência de Tema $(n=11)$; Intercorrência de acesso a pesquisa $(n=9)$; Relevância dos resultados obtidos $(n=6)$. Observa-se a seguir o produto dos artigos obtidos para a inclusão no estudo (Quadro

Quadro 1: Registro e Síntese dos Dados selecionados na pesquisa

Autor Ano

Papel de metiltransferases de proteínas no desenvol-

Sakamoto 2014 vimento e prognóstico de leucemias linfóides agudas da infância

\section{Objetivo}

Verificar o papel da expressão de genes codificadores de metiltransferases de proteínas no desenvolvimento e prognóstico de leucemias linfóides agudas da infância

\section{Conclusão}

Comprovou-se, em linhagem celular de leucemia, que o silenciamento do gene SMYD2 é capaz de reduzir a taxa de proliferação celular, o que pode ser causado por alterações da atividade de metiltransferase-H3K9 desse gene, tanto ao nível de proteínas histonas quanto não-histonas

\section{Contribuição}

Trata-se de um estudo piloto em que é possivel identificar níveis elevados de expressão de genes codificadores de metiltransferases de lisina em amostras de Leucemia Linfóide Aguda da infância, quando comparadas às medulas não neoplásicas 
Noh et al., 2014

Tao, et al, 2014

Tachibana, et al., 2011 p53 regula negativamente a expressão do gene SETDB1 durante morte celular induzida por paclitaxel

A dimetilação de histona metiltrans -ferase G9a e H3K9 inibe a auto renovação de células-tronco cancerígenas de glioma

Proteína contendo domínio SET, G9a, é uma nova preferida pela lisina Histona Metiltransferase de Mamíferos com Hiperatividade e Seletividade específica para lisinas 9 e 27 da histona $\mathrm{H3}$
Avaliar se a Paclitaxe afeta a expressão de SETDB1 HMTase durante a morte celular e se Paclitaxel induz a morte celular por meio da regulação G2 / M em células de câncer de pulmão humano

Descrever o papel da Histona 3 na metilação da lisina 9 (H3K9me2) e seu metiltransferases G9a em células tronco cancerosas

Avaliar os mecanismos responsáveis durante a regulação dos processos nucleares das histonas H3 como controle de transcrição e condensação mitótica
Os estudos concluíram que o tratamento com PTX, de fato, induz $\mathrm{p} 53$ e regula negativamente SETDB1 no transcrito. A atividade do promotor SETDB1 é aumentada para aproximadamente 30 vezes em condição normal, mas a atividade é significativamente inibida no grupo tratado com PTX. Além disso, a transfecção de p53 inibe a atividade do promotor SETDB1

Os resultados indicam metilação da histona-transferase G9a e H3K9 atuam como a principal mudança para regular a auto renovação do glioma células-tronco, por meio da repressão direta nos promotores de CD133 e Sox2

Os dados apontam que G9a tem uma enzima de Natureza distinta de Suv39 h1 e de seu homólogo h2, e que G9a, marcado com proteína fluorescente, foi localizado no domínio cromático repressivo em lócus centroméricos, na mesma região em que as proteínas da familia Suv39 h1. Isso pode indicar que G9a pode contribuir para a organização do alto estrutura da cromatina de ordem de locus não centroméricos.
Os estudos mostraram que 0 gene SETDB1 possui expressão ditada pelo complexo repressor dependente de p53 relatado em sua região promotora. Esse estudo possui relevância por ser o primeiro trabalho que indica que a expressão do gene SETDB1 é regulada por um supressor de tumor p53.

Foi verificado um conjunto de hipóteses acerca das variedades de evidências que apontaram que a repressão de G9a é H3K9me2-dependente e foi um das principais aspectos considerados para estabelecer a auto renovação das células-tronco do câncer de glioma

O estudo apresenta uma nova compreensão de que G9a é uma preferência da lisina H3 HMTase, mostrando atividade de HMTase mais forte do que Suv39 h1. Os experimentos de mutagênese demonstraram que 0 atividade enzimática elevada de G9a também é dependente do primeiro resíduo central no domínio SET, com arginina 899 em camundongo, mostrando mudança de histidina

320 para arginina nessa mesma posição em Suv39 h1 


\section{artigo}

Amorim, M. T., Cruz, A. C. R., Ferreira, J. F. L., Oliveira, D. J. S., Melo, C. A., Pinto, C. C., Neto, W. F. F., Holanda, G. M

Reação de Metilação da Lisina Metiltransferase e Silenciamento de Genes no Rastreio do Desenvolvimento do Câncer

\begin{tabular}{|c|c|c|c|c|}
\hline $\begin{array}{l}\text { Tapias, et al., } \\
2019\end{array}$ & $\begin{array}{c}\text { Expressão da Lisina Metil- } \\
\text { transferase SETDB1 Principal } \\
\text { e Pró-oncogênica em Câncer } \\
\text { de Pulmão }\end{array}$ & $\begin{array}{c}\text { Investigar o } \\
\text { significado clínico } \\
\text { da expressão de } \\
\text { SETDB1 nas duas } \\
\text { formas principais de } \\
\text { carcinoma pulmo- } \\
\text { nar de células não } \\
\text { pequenas (NSCLC), } \\
\text { ou seja, adenocarci- } \\
\text { noma e carcinoma de } \\
\text { células escamosas, a } \\
\text { partir de uma meta- } \\
\text {-análise de conjuntos } \\
\text { de diversos dados } \\
\text { transcriptômicos e } \\
\text { uma revisão siste- } \\
\text { mática da literatura }\end{array}$ & $\begin{array}{l}\text { O estudo revelou níveis ele- } \\
\text { vados de mRNA, SETDB1 } \\
\text { no NSCLC em comparação } \\
\text { com os tecidos de controle } \\
\text { não cancerosos. Os dados } \\
\text { sugerem a possibilidade } \\
\text { de usar Nível de mRNA SE- } \\
\text { TDB1 como um marcador } \\
\text { para a detecção precoce de } \\
\text { NSCLC }\end{array}$ & $\begin{array}{c}\text { Os resultados sugerem uma } \\
\text { base sólida para pesquisas } \\
\text { futuras para avaliar SET- } \\
\text { DB1 como um biomarcador } \\
\text { diagnóstico e / ou seu uso } \\
\text { potencial como um alvo } \\
\text { terapêutico em carcinoma } \\
\text { pulmonar de células não } \\
\text { pequenas }\end{array}$ \\
\hline $\begin{array}{l}\text { Rowbothan, et al., } \\
\text { (2018) }\end{array}$ & $\begin{array}{l}\text { As metiltransferases e des- } \\
\text { metilases H3K9 controlam } \\
\text { as células de propagação do } \\
\text { tumor do pulmão e a pro- } \\
\text { gressão do câncer de pulmão }\end{array}$ & $\begin{array}{l}\text { Avaliar se a histona } \\
\text { metiltransferase } \\
\text { G9a, relatada como } \\
\text { um alvo terapêutico } \\
\text { em muitos cânceres, } \\
\text { se caracteriza como } \\
\text { um supressor de } \\
\text { células agressivas } \\
\text { de propagação de } \\
\text { tumores pulmonares } \\
\text { (TPCs) }\end{array}$ & $\begin{array}{l}\text { O estudo destaca a impor- } \\
\text { tância de escolher o melhor } \\
\text { modelo de heterogeneidade } \\
\text { celular. Foi possivel concluir, } \\
\text { baseado principalmente em } \\
\text { linhagens celulares e nos } \\
\text { tumores inteiros, que G9a é } \\
\text { oncogênico e um bom alvo } \\
\text { para terapia epigenética }\end{array}$ & $\begin{array}{c}\text { Os autores apresentam } \\
\text { uma nova compreensão no } \\
\text { contexto celular e como as } \\
\text { populações tumorais espe- } \\
\text { cíficas são fundamentais na } \\
\text { análise de alvo reguladores } \\
\text { epigenéticos no câncer para } \\
\text { futuro rastreio de progressão } \\
\text { e desenvolvimento de estra- } \\
\text { tégias terapêuticas. }\end{array}$ \\
\hline iutor & & & & \\
\hline
\end{tabular}

1) e o resumo esquemático dos principais achados (Figura 1).

\section{DISCUSSÃO}

A compreensão dos mecanismos epigenéticos moleculares vem se desenvolvendo ao longo dos anos, melhorando substancialmente a compreensão sobre os mecanismos de ocorrência de modificação pós tradução de histonas (PTMs) e regulação da transcrição em condições normais e patológicas, com ênfase no rastreio de diversos tipos de câncer. Nessa perspectiva, apesar da prevalência de evidências incipientes sobre a interação das metiltranferases de lisina entre si e entre outras proteínas, é provável que ocorra um controle transcricional no nível de atividade do promotor de um gene codificador de uma metiltransferase regulada por outra metiltransferase de proteína, o que pode conceber a existência de um regulador comum ou coordenado, que seja ativo na cadeia de diversas metiltransferases de proteínas, podendo indicar a presença de um câncer 2 .

Sob uma abordagem inicial, tratando dessa perspectiva, o estudo realizado por Sakamoto LHT, et al. (2014)19 verificou que, após observação clínico-laboratorial de genes expressos em pacientes, estes produtos expressos que possuem associação na regulação transcricional, estão supostamente relacionados a algum papel na leucemogênese ou no prognóstico de pacientes. Um achado intrigante no seu estudo, revelou uma alta taxa de correlação a partir dos níveis de expressão dos genes que foram apresentados distintamente expressos em leucemias.

Relacionando-se com Noh HJ, et al. (2014)20, realizado com células de linhagem pulmonar, foi evidenciado uma reexpressão da proteína p53, com subsequente diminuição de SETDB1 - metiltransferase de lisina - com atividade $\mathrm{H} 3 \mathrm{~K} 9$ me em tra- tamento com quimioterápico (paclitaxel), que corrobora durante o processo de compactação da cromatina durante a diferenciação, desenvolvimento e morte celular. Ainda, o mesmo estudo descreveu que p53, participa ligando-se ao promotor de SET$\mathrm{DB} 1$ e induzindo $\mathrm{H} 3 \mathrm{~K} 9 \mathrm{me}$, sendo designada à expressão relacionada subsequente a metiltransferase SUV39H1. Portanto, o complexo $\mathrm{p} 53$, induzido por quimioterápico aumenta $\mathrm{H} 3 \mathrm{~K} 9 \mathrm{me} 3$ na região SETDB1, e esse aumento pode ser capaz de diminuir a ação do promotor, ocasionando em uma baixa expressão deste gene.

Como descrito anteriormente, SETDB1 possui importante papel na detecção de tumores, por meio da expressão significativa associada a carcinoma hepatocelular e melanoma. Por outro viés, o silenciamento de SETDB1, parece inibir proliferação celular, invasão celular, crescimento tumoral e metástase em diversos tipos de câncer. SETDB1 pode impactar o fenótipo do cân- 
Figura 1: Resumo esquemático dos principais achados

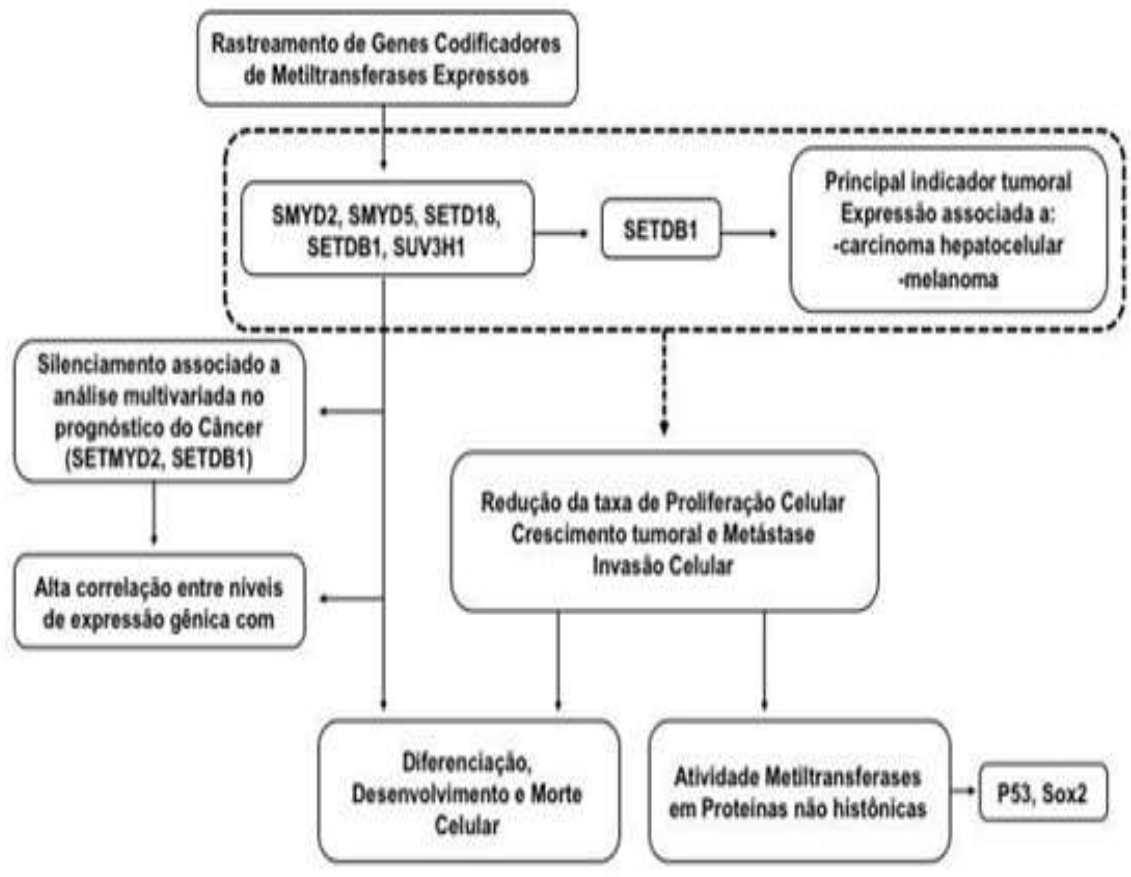

Fonte: Amorim MT, et al., 202

cer, agindo em diferentes substratos, tendo como seu principal alvo $\mathrm{H} 3 \mathrm{~K} 9$ e além disso, outros supressores de alta relevância também são descritos, incluindo o supressor de tumor TP53 e quinase AKT, sendo um importante determinante em diversos eventos moleculares, não somente à nível da cromática. Tapias PC, et al. (2019)21, conseguiu identificar no seu estudo superexpressão de SETDB1 relacionada às características clínicas de pacientes com câncer de pulmão com dois tipos de câncer de pulmão de células não pequenas, a saber adenocarcinoma e carcinoma de células espinhosas.

Estudo realizado por Tao $\mathrm{H}$, et al. (2014)22, verificou-se que a maioria das células positivas para CD133 eram H3K$9 \mathrm{me} 2$ negativo, tanto nos tecidos de glioma quanto em cultura celular, apesar da maioria das células cancerosas terem sido detectadas $\mathrm{H} 3 \mathrm{~K} 9 \mathrm{me} 2$ imuno positivo. Os autores associaram esses resultados com G9a-H3K9 dependente de uma das barreiras fundamentais de auto-renovação de células tronco cancerígenas. De modo a testar essas hipóteses, foi observada a perda e ganho de função dem G9a e com isso, descobriram um inibidor seletivo (bix01294), responsável por estimular Sox2 e CD133 e corroborar para o aumento taxa de formação de esferas cancerígenas de glioma em células-tronco.

Segundo Tachibana M, et al (2007) $)^{23}$ , em estudo realizado com células germinativas, os autores descrevem relação restrita da expressão da proteína G9a a espermatogônias e espermatócitos leptótenos iniciadores. De modo a avaliar a função de G9a no desenvolvimento celular, foi analisada a expressão de G9a em testículos e foi encontrado perfil de expressão de G9a; GLP semelhante ao de anticorpos PLFZ, sugerindo que a expressão dessas proteínas não é constante, mas regulada constantemente durante a espermatogênese. Foi verificado uma dinâmica de metilação de $\mathrm{H} 3 \mathrm{~K} 9 \mathrm{du}$ rante a prófase meiótica masculina, a partir da qual H3K9me2.1, mediada por G9a foi perdida nos espermatócitos paquitênicos. Estes dados sugerem que a metilação $\mathrm{H} 3 \mathrm{~K} 9$ durante a prófase meiótica é regulada de forma dinâmica a partir da combinação das proteínas e dos genes expressos. Portanto, os insights fornecidos permitem sugerir como os efeitos das reações de metilação e desmetilação de $\mathrm{H} 3 \mathrm{~K} 9$ podem regular funções primordiais que podem afetar o desenvolvimento e a diferenciação celular.

Esses reguladores epigenéticos podem ser considerados alvos contra o câncer muito atraentes e em vista disso, a ênfase por estudos que avaliem a eficácia de estratégias de rastreio da progressão desses fatores, vem se tornando cada vez mais necessária em consideração ao comportamento de células tumorais. Rowbotham SP, et al. $(2018)^{24}$, descobriram que a inibição de G9a, leva à função de células de propagação de tumor aumentada e impulsiona a propagação do tumor metastático, também identificaram G9a reprimindo uma assinatura de gene associada a reguladores em KRAS e ECM mutantes, a citar Mmp10, que participa da tumorigenicidade de células tumorais depletadas em G9a. Além disso, a inibição de $\mathrm{H} 3 \mathrm{~K} 9 \mathrm{KDM}$, também descrita pelos autores, pode ser um tratamento alternativo benéfico para adenocarcinoma de pulmão avançado. Dessa forma, ao se avaliar as dependências epigenéticas de células de propagação tumorais, o estudo pôde revelar um potencial alternativo para intervenção terapêutica em câncer de pulmão avançado.

\section{CONCLUSÃO}

Em concordância com os resultados apresentados, pode-se perceber que após o advento de técnicas para análises genômicas, a capacidade do rastreio abrangente dos estudos acerca do epigenoma de cânceres humanos, desenvolveu-se e abriu novos precedentes para o fornecimento de informações precisas de estratégias de prevenção, diagnóstico e prognóstico associado ao desenvolvimento dessa patologia. Aqui, fornecemos uma visão geral atualizada $e$ específica dos efeitos celulares e moleculares subjacentes à atividade de $\mathrm{H} 3 \mathrm{~K} 9$ no desenvolvimento e progressão do câncer, apresentando as diversas estratégias de direcionamento atuais em diferentes tipos e estágios de câncer, com efeitos promissores 


\section{artigo}

Amorim, M. T., Cruz, A. C. R., Ferreira, J. F. L., Oliveira, D. J. S., Melo, C. A., Pinto, C. C., Neto, W. F. F., Holanda, G. M

Reação de Metilação da Lisina Metiltransferase e Silenciamento de Genes no Rastreio do Desenvolvimento do Câncer

associados a sua progressão, corroborando como agente autônomo que, em conjun- to com os avanços tecnológicos, poderão auxiliar para a compreensão da "paisagem epigenômica" e sua relação com os perfis de expressão gênica.

\section{REFERÊNCIAS}

1. WHO. Cancer. disponivel em: http://www.who.int/cancer/en/. acesso em: 28 dez. 2020.

2. Li J. et al. Role of several histone lysine methyltransferases in tumor development. biomedical reports, 2016; 4(3): 293-299.

3. Reece JB, Campbell NA. biology. 6. ed. boston: benjamin cummings, 2002.

4. Jenuwein T, Allis CD. Translating the histone code. science, 2001; 293 : $1074-1081$.

5. Bernstein $\mathrm{BE}$, et al. Review the mammalian epigenome. cell, v. 128, p. 669-681.

6. Lima N, et al. RM1 semiempirical model: chemistry, pharmaceutical research, molecular biology and materials science. journal of the brazilian chemical society, 2018; 30(4): 683-716.

7. Kouzarides T. Review chromatin modifications and their function. cell, 2007; 128: 693-705.

8. Couture JF, et al. Structural origins for the product specificity of set domain protein methyltransferases. proceedings of the national academy of sciences, 2008; v. 105, n. 52, p. 20659-20664.

9. Kastan MB, Bartek J. Cell-cycle checkpoints and cancer. nature, 2004; 432 316-323.

10. Tamaru H, Selker EU. A histone h3 methyltransferase controls dna methylation in neurospora crassa. nature, 2001; 414: 277-283.

11. Rountree MR, Selker EU. DNA methylation and the formation of heterochromatin in neurospora crassa. heredity, 2010; 105: 38-44.

12. Jackson JP, et al. Control of cpnpg dna methylation by the kryptonite histone h3 methyltransferase. nature, 2002; 416: 556-560.

13. Malagnac $F$, et al. An arabidopsis set domain protein required for maintenance but not establishment of dna methylation. embo j, 2002; 21: 68426852

14. Lehnertz B, et al. Activating and inhibitory functions for the histone lysine methyltransferase $\mathrm{g} 9 \mathrm{a}$ in $\mathrm{t}$ helper cell differentiation and function. $\mathrm{j}$ exp med, 2010: 915-922.

15. Dong KB, et al. DNA methylation in es cells requires the lysine methyltransferase g9a but not its catalytic activity. embo j, 2008; 27: 2691-2701.

16. Espada J, et al. Human dna methyltransferase 1 is required for maintenance of the histone h3 modification pattern. j biol chem 2004; 279: 37175-37184.

17. Estève PO, et al. Direct interaction between dnmt 1 and g9a coordinates dna and histone methylation during replication. genes dev, 2006; 20: 30893103.

18. Tsumura a, et al. Maintenance of self-renewal ability of mouse embryonic stem cells in the absence of dna methyltransferases dnmt 1 , dnmt3a and dnmt3b. genes cells, 2006; 11: 805-814

19. Sakamoto LHT. Papel de metiltransferases de proteínas no desenvolvimento e prognóstico de leucemias linfóides agudas da infância. rev. inst. biol, 2014, 122: 64-71.

20. Noh HJ, et al. p53 down-regulates setdb1 gene expression during paclitaxel induced-cell death. biochem biophys res commun, 2014; 446(1): 43-48.

21. Tapias PC, et al. Expression of the major and pro-oncogenic h3k9 lysine methyl transferase setdb1 in non-small cell lung. cancers, 2019; 1124: 901915.

22. Tao h, et al. Dimethylation of histone methyltransferase g9a and h3k9 inhibits self-renewal of glioma cancer stem cells. mol cell biochem, 2014; 394: 23-30.

23. Tachibana $M$, et al. Set domain-containing protein, g9a, is a novel lysine-preferring mammalian histone methyltransferase with hyperactivity and specific selectivity to lysines 9 and 27 of histone h3. j biol chem, 2011; 276: 25309-25317.

24. Rowbotham SP, et al. H3K9 methyltransferases and demethylases control lung tumor spreading cells and the progression of lung cancer. nat commun, 2018, 9: 45-59. 